Check for updates

Cite this: J. Mater. Chem. B, 2020, 8, 7667

\section{Reactive oxygen species (ROS) production in HepG2 cancer cell line through the application of localized alternating magnetic field}

\author{
Alberto Sola-Leyva, $\dagger^{\mathrm{a}}$ Ylenia Jabalera, (D) $\dagger^{\mathrm{b}}$ María A. Chico-Lozano, ${ }^{\mathrm{b}}$ \\ María P. Carrasco-Jiménez, ${ }^{* a}$ Guillermo R. Iglesias (DD ${ }^{* c}$ and \\ Concepción Jimenez-Lopez ${ }^{b}$
}

\begin{abstract}
Recent studies have shown the potential of magnetic hyperthermia in cancer treatments. However, the underlying mechanisms involved have not been yet fully described. In particular, the cell death related to magnetic hyperthermia observed in cultures incubated with low concentration of magnetic nanoparticles and under a low intensity alternating magnetic field, in which a macroscopic temperature rise is not observed, is still not understood. In the present study, we investigate the production of intracellular Reactive Oxygen Species (ROS) as a mechanism to induce cell death under these conditions. In this study, the production and influence of ROS on the viability of HepG2 human hepatoma cells (used as a model cell line) are analyzed under the application of variable magnetic fields using hyperthermia agents, such as biomimetic magnetic nanoparticles (BMNPs) mediated by magnetosome MamC protein from Magnetococcus marinus MC-1. The results show that intracellular ROS production increases up to $\sim 90 \%$ following upon the exposure of AMF to HepG2 cells containing BMNPs, which could determine the loss of cell viability (up to $\sim 40 \%$ reduction) without a significant rise in temperature. Such ROS production is linked to mitochondrial dysfunction caused by the application of AMF to cells containing BMNPs.
\end{abstract}

Received 22nd May 2020

Accepted 7th July 2020

DOI: $10.1039 / d 0 t b 01306 d$

rsc.li/materials-b

\section{Introduction}

Magnetic hyperthermia has gained interest as one of the most promising alternatives for the local treatment of tumors. It is based on the use of hyperthermia agents (like iron oxide magnetic nanoparticles or other metallic nanoparticles) to produce localized heat under the influence of alternating magnetic field (AMF). ${ }^{1}$ The temperature increment of up to 42-46 ${ }^{\circ} \mathrm{C}$ at the tumor site results in the death of cancer cells by apoptosis or necrosis. ${ }^{2-4}$ However, to induce such a temperature rise, high AMF needs to be applied and/or high concentrations of magnetic nanoparticles (in the order of $\mathrm{mg} \mathrm{mL}^{-1}$ ) are required. The required AMF and nanoparticle concentrations are usually above the allowed limit for in vivo treatments $\left[H \cdot f<5 \times 10^{9}\right],{ }^{5}$ where nanoparticle concentrations are in the

\footnotetext{
${ }^{a}$ Department of Biochemistry and Molecular Biology I, University of Granada, 18071 Granada, Spain.E-mail: albertosola@ugr.es, maria23chl@correo.ugr.es, mpazcj@ugr.es

${ }^{b}$ Department of Microbiology, University of Granada, 18071 Granada, Spain. E-mail: yjabalera@ugr.es, cjl@ugr.es

'Department of Applied Physics, University of Granada, 18071 Granada, Spain. E-mail: iglesias@ugr.es

$\dagger$ These authors contributed equally to this work.
}

order of $\mu \mathrm{g} \mathrm{mL}{ }^{-1}$ to avoid potential cytotoxic effects. ${ }^{6}$ In fact, there are few studies that have reported temperature increments up to cytotoxic levels in vitro, but in all these cases, either the nanoparticle concentration used was too high and/or the pairs $(f, H)$ used were not within the biological range. ${ }^{7-9}$

However, surprisingly, some authors have observed a kind of cytotoxic effect, in which even upon the application of AMF in different cell lines incubated in vitro with magnetic nanoparticle concentrations in the order of $<500 \mu \mathrm{g} \mathrm{mL} \mathrm{m}^{-1}$, no detectable macroscopic temperature rise was observed (or estimated). ${ }^{10-14}$ No explanation for such a phenomenon is plausible at the moment. Our hypothesis and the focus of the present paper is that the application of AMF to cell cultures incubated with magnetic nanoparticles triggers some biological effects that are responsible for cell death even if the concentration of these nanoparticles is too low to induce a detectable temperature rise.

In this context, one of the biological effects, that may result upon the application of AMF, is the generation of increased levels of intracellular reactive oxygen species (ROS). In fact, some studies have shown that magnetic nanoparticles produce ROS by Fenton and Haber-Weiss iron-mediated reactions ${ }^{15}$ and other authors have proposed cell damage by ROS increase upon the application of AMF. ${ }^{16}$ ROS can damage DNA, proteins, and 
hence cellular function. ${ }^{17}$ This suggests that the generation of ROS either by the magnetic nanoparticles that are in the cells and/or by AMF could be one of the underlying mechanisms causing cell death. However, it is not known whether intracellular ROS production in this context can occur without detectable temperature rise or if such intracellular ROS production is linked to the rise in temperature caused by hyperthermia. Therefore, understanding whether or not ROS production occurs upon the application of AMF and whether or not its production requires a temperature rise, may provide new tools to increase the efficiency of hyperthermia treatments against cancer while keeping low the doses of magnetic nanoparticles that need to be injected.

To address this study, biomimetic magnetic nanoparticles (BMNPs) synthezized by the mediation of magnetosome MamC protein from the magnetotactic bacterium Magnetococcus marinus MC-1 were used as magnetic hyperthermia agents and HepG2 human hepatoma cell lines were used as a cell model. Then, the ability of BMNPs as hyperthermia agents, their biocompatibility, and internalization on cells as well as the in vitro temperature increment and ROS production were evaluated.

\section{Experimental}

\subsection{BMNPs synthesis}

MamC was expressed and purified as recombinant protein following the protocol described in the literature. ${ }^{18}$ Escherichia coli TOP10 (Life Technologies: Invitrogen, Grand Island, NY, USA) was transformed with the help of plasmid pTrcHis-TOPO (Life Technologies: Invitrogen), which was used as a vector of the MamC protein-coding gene (Mmc1_2265) coupled to a hexahistidine tag coding sequence at its $5^{\prime}$ terminus. The cells were grown at $37{ }^{\circ} \mathrm{C}$ in Luria-Bertani (LB) broth supplemented with $50 \mathrm{mg} \mathrm{mL}{ }^{-1}$ of ampicillin. After 5 hours of contact with isopropyl- $\beta$-D-thiogalactopyranoside (IPTG, Fisher BioReagents, Pittsburgh, PA, USA), the expression of recombinant MamC was induced. Once expressed, the purification of the protein was carried out under denaturing conditions by fast protein liquid chromatography (FPLC, GE Healthcare) and immobilized-metal affinity chromatography (IMAC, GE Healthcare, Chicago, IL, USA). Finally, the fractions containing MamC were refolded at $4{ }^{\circ} \mathrm{C}$ through dialysis using $1 \mathrm{~L}$ of the buffers A (Tris $50 \mathrm{mM}, \mathrm{NaCl}$ $150 \mathrm{mM}$, urea $6 \mathrm{M}, \mathrm{pH} 8.5$ ) and B (Tris $50 \mathrm{mM}, \mathrm{NaCl} 150 \mathrm{mM}$, $\mathrm{pH}$ 8.5) as the starting and end points, respectively. The purity of the protein was evaluated by SDS-PAGE electrophoresis.

The synthesis of BMNPs was carried out at $25^{\circ} \mathrm{C}$ and 1 atm total pressure obtained from oxygen-free solutions protocol described in ref. 18 and 19 containing $3.5 \mathrm{mM} \mathrm{Na}_{2} \mathrm{CO}_{3}, 3.5 \mathrm{mM} \mathrm{NaHCO}$, $2.78 \mathrm{mM} \mathrm{Fe}\left(\mathrm{ClO}_{4}\right)_{2}, 5.56 \mathrm{mM} \mathrm{FeCl}_{3}$, and $10 \mu \mathrm{g} \mathrm{mL}{ }^{-1}$ recombinant MamC at a $\mathrm{pH}$ value of 9. All the experiments were performed under anaerobic conditions inside an anaerobic Coy chamber (96\% $\mathrm{N}_{2} / 4 \% \mathrm{H}_{2}$, Coy Laboratory Products, Grass Lake, MI, USA). The samples were incubated for 30 days and then the solids were magnetically concentrated, washed three times with deoxygenated Milli-Q water, and stored in HEPES buffer $(\mathrm{pH}$ 7.4) inside the Coy Chamber at $25{ }^{\circ} \mathrm{C}$.

\subsection{BMNPs characterization}

Transmission electron microscopy (TEM) analyses were performed with a STEM Philips Model CM20 microscope on ultrathin sections $(50-70 \mathrm{~nm})$ prepared by embedding the nanoparticles in the Embed 812 resin and then cutting them using a Reichert Ultracut S microtome (Leica Microsystems GmbH, Wetzlar, Germany). The ImageJ 1.47 software was used to measure particle sizes on multiple micrographs with over 1000 nanoparticles measured to ensure reproducibility. Hysteresis cycles were carried out at $300 \mathrm{~K}$ and $5 \mathrm{~K}$ by using a superconducting quantum interference device (SQUID) $5 \mathrm{~T}$ magnetometer (Quantum Design MPMS XL, San Diego, CA, USA). Electrophoretic mobility measurements were carried out in a Zetameter Nano-ZS (Malvern Instruments, Malvern, UK) at $25{ }^{\circ} \mathrm{C}$. The stock suspensions of BMNPs were prepared in $20 \mathrm{~mL}$ of oxygen-free $\mathrm{NaClO}_{4}(10 \mathrm{mM})$. The aliquots of $200 \mu \mathrm{L}$ from each stock were suspended in flasks containing oxygenfree $\mathrm{NaClO}_{4}$, and the $\mathrm{pH}$ was adjusted from 2 to 9. The samples were sonicated for $2 \mathrm{~min}$, and the electrophoretic mobility was immediately measured.

Basic mineral characterization [thermogravimetric analyses, specific surface area by Brunauer-Emmett-Teller (BET), and ZF-ZFC curves] can be found in the literature. ${ }^{18,20}$ The BMNPs used in the present study are superparamagnetic, contain up to $5 \mathrm{wt} \%$ MamC, have the specific surface area of $\sim 90 \mathrm{~m}^{2} \mathrm{~g}^{-1}$, and the blocking temperature of $\sim 145 \mathrm{~K}^{20}$

\subsection{Calorimetric and specific absorption rate determination}

The Specific Absorption Rate (SAR) is estimated from the measurement of time-dependent calorimetric heating in a home AMF. Briefly, it consists of a four-turn air-cored coil made of watercooled copper pipe as the part of a resonant circuit powered by an AC generator having an inner diameter of $4 \mathrm{~mm}$. Two experiments were performed: (i) five frequencies were selected, namely $136 \mathrm{kHz}$, $160 \mathrm{kHz}, 200 \mathrm{kHz}, 245 \mathrm{kHz}$, and $380 \mathrm{kHz}$, with a fixed magnetic field strength of $10 \mathrm{kA} \mathrm{m}^{-1}$ (ii) five magnetic field strengths were analyzed, namely $6 \mathrm{kA} \mathrm{m}^{-1}, 10 \mathrm{kA} \mathrm{m}^{-1}, 12.5 \mathrm{kA} \mathrm{m}^{-1}, 15 \mathrm{kA} \mathrm{m}^{-1}$, and $20 \mathrm{kA}$ $\mathrm{m}^{-1}$, with a fixed frequency of $136 \mathrm{kHz}$. Both the frequency and the magnetic field strength were measured in the center of the coil using a magnetic probe (NanoScience Laboratories Ltd, Staffordshire, UK) with a resolution of $10 \mu \mathrm{T}$. The change in temperature $\mathrm{d} T v s$. time $\mathrm{d} t$ was measured with an optical fiber thermometer (Optocon AG, Dresden, Germany) during the first $20 \mathrm{~s}$ after turning on the field. The samples to be evaluated were placed in the Eppendorf plastic tubes (1.5 mL sample volume), containing $0.5 \mathrm{~mL}$ of sample volume at a concentration of $10 \mathrm{mg} \mathrm{mL} \mathrm{m}^{-1}$ in HEPES buffer.

The SAR value and Intrinsic Loss Power (ILP), defined as SAR $\left(H^{2} f\right)^{-1}$ to compare the performance of measured NPs under different field conditions, were calculated by the classical definition and using eqn (1) and (2): ${ }^{21,22}$

$$
\mathrm{SAR}=\left(\frac{C \cdot V_{\mathrm{s}}}{m}\right) \frac{\mathrm{d} T}{\mathrm{~d} t}
$$




$$
\mathrm{ILP}=\frac{\mathrm{SAR}}{f H_{0}^{2}}
$$

Finally, to evaluate the possible interference of the cell growth media with alternating magnetic field, these media were evaluated and compared with those obtained when BMNPs were suspended in the HEPES buffer. In this case, a fixed frequency of $136 \mathrm{kHz}$ and a fixed magnetic field strength of $20 \mathrm{kA} \mathrm{m}^{-1}$ were used.

A thermal imaging camera FLIR 60, with $320 \times 240$ pixels IR resolution and thermal sensitivity $<0.045{ }^{\circ} \mathrm{C}$ (FLIR Systems, Inc. Wilsonville, Oregón, USA), was used to measure the maximum temperature reached by the different concentrations of BMNPs (from 0.1 to $20 \mathrm{mg} \mathrm{mL} \mathrm{m}^{-1}$ ). Although the AMF was applied for 1.5 hours, the images were taken after 5 minutes of the treatment (time after which differences in the samples were not observed).

\subsection{Cell culture}

The human hepatoma HepG2 cell line used in this work was obtained from the European Collection of Animal Cell Cultures (Salisbury, UK). The cells were cultured in Minimum Essential Medium (MEM) including 10\% heat-inactivated fetal bovine serum (FBS) (MEM/10\% FBS) supplemented with $2 \mathrm{mM}$ L-glutamine, $1 \%$ non-essential amino acids, $100 \mathrm{U} \mathrm{mL}$ penicillin, and $100 \mu \mathrm{g} \mathrm{mL} \mathrm{mL}^{-1}$ streptomycin. The cell cultures were maintained in a humid atmosphere with $5 \% \mathrm{CO}_{2}$ at $37{ }^{\circ} \mathrm{C}$ and subcultured at a ratio of 1:10 once a week or when an experiment required it.

\subsection{BMNPs internalization}

For the quantitative analysis of nanoparticle uptake, HepG2 cells (300000 cells per well) were seeded in 12-well plates. Subsequently, $300 \mu \mathrm{g} \mathrm{mL} \mathrm{m}^{-1}$ BMNPs were added. After $24 \mathrm{~h}$, cells were washed with PBS, trypsinized, transferred to $2 \mathrm{~mL}$ tubes, and centrifuged at $1000 \mathrm{rpm}$ for $5 \mathrm{~min}$. Then, the cell pellets formed were dissolved in $37 \% \mathrm{HCl}$, mixed with $10 \%$ $\mathrm{H}_{2} \mathrm{O}_{2}$, and incubated for $20 \mathrm{~min}$ at room temperature. Subsequently, the samples were treated with $1 \mathrm{~mL}$ of $1 \%$ potassium thiocyanate in Milli-Q water, and their absorbance was measured at $490 \mathrm{~nm}$. The concentration of nanoparticles in the samples was calculated referencing the absorbance obtained to a standard curve and the endogenous iron of cells was subtracted.

\subsection{Cell proliferation assay}

HepG2 cells were seeded onto 96-well plates (10 000 cells per well) and grown in MEM/10\% FBS for $24 \mathrm{~h}$. After $24 \mathrm{~h}$, the medium was removed and $100 \mu \mathrm{L}$ of fresh medium containing BMNPs $\left(300 \mu \mathrm{g} \mathrm{mL}{ }^{-1}\right)$ or just medium as control were added. Cell viability was assayed by the crystal violet staining assay using a cell-numberbased standard curve as previously reported ${ }^{23}$ in the presence or absence of AMF for $2 \mathrm{~h}$. The absorbance of crystal violet in each well was measured at a wavelength of $590 \mathrm{~nm}$ directly in plates using a microplate reader (HTX Microplate Reader BioTek Instruments, Vermont, USA).

\subsection{Intracellular ROS analysis}

Intracellular ROS were studied by using the fluorometric intracellular ROS kit (MAK143, Sigma-Aldrich, Madrid, Spain) following the manufacturer's recommendations. This kit provides a fluorogenic sensor which reacts with ROS, resulting in a fluorometric product proportional to the amount of ROS present in live cells. In order to carry out these experiments, cells were seeded onto 96-well black plates with clear bottoms for fluorometric assays (20 000 cells per well) in MEM/10\% FBS for $24 \mathrm{~h}$ in the presence or absence of NMNPs. The plates were previously cut into 4-well blocks to fit the requirements of the instrument that generates AFM. Then a volume of $100 \mu \mathrm{L}$ per well of Master Reaction Mix containing the fluorogenic sensor was added and incubated for $1 \mathrm{~h}$. Then, the cells were exposed to AMF for 2 h. $0.5 \mathrm{mM}$ of $\mathrm{H}_{2} \mathrm{O}_{2}$ was used as a positive control and the fluorescence intensity was measured at $\lambda_{\mathrm{ex}}=490 / \lambda_{\mathrm{em}}=525 \mathrm{~nm}$.

\subsection{Cell micrographs by transmission electron microscopy}

HepG2 cells, suspended in 1-5 mL tubes, were exposed to AMF under the condition described above. Then TEM analyses were performed as previously described in ref. 24. Briefly, glutaraldehyde and paraformaldehyde in cacodylate buffer were used to fix the cell pellets. As a postfixed solution, $1 \% \mathrm{OsO}_{4}$ containing $1 \%$ potassium ferrocyanide was added and kept standing for $1 \mathrm{~h}$ at $4{ }^{\circ} \mathrm{C}$ in darkness. A series of washes were performed, first by using $0.15 \%$ tannic acid in cacodylate buffer, then cacodylate buffer, $\mathrm{H}_{2} \mathrm{O}$, and finally, the samples were incubated in $2 \%$ uranyl acetate for $2 \mathrm{~h}$ and washed few times with $\mathrm{H}_{2} \mathrm{O}$. Then, $50 \%$ to $100 \%$ ethanol solutions were used for dehydration, and as the last step, the samples were embedded in resin. Ultrafine sections were prepared by using a Leica Ultramicrotome $\mathrm{R}$ and contrasted by using $1 \%$ aqueous uranyl acetate for $5 \mathrm{~min}$ and lead citrate in a $\mathrm{CO}_{2}$-depleted atmosphere. To visualize the ultrafine sections, A Zeiss Libra Plus 120 electron microscope was used.

\section{Results and discussion}

\subsection{Nanoparticle characterization}

The particle size and morphology of BMNPs were analyzed by TEM images. Fig. 1A shows that biomimetic crystals BMNPs exhibited well-defined faces. These BMNPs show sizes ranging from 20 to $60 \mathrm{~nm}$, with an average crystal size of $37 \pm 7 \mathrm{~nm}$ (Fig. 2B). The hysteresis cycles of BMNPs showed a typical ferromagnetic behavior at $5 \mathrm{~K}$, while at $300 \mathrm{~K}$, these nanoparticles showed zero coercivity, which indicates their superparamagnetic character (Fig. 1C). The isoelectric point of BMNPs was 4.4 (Fig. 1D), indicating the negative charge of these nanoparticles at physiological $\mathrm{pH}$. The negative charge and the superparamagnetic character of BMNPs prevent their magnetic aggregation in the absence of an external magnetic field, while when this field is applied, BMNPs respond efficiently with a magnetic saturation of $54 \mathrm{emu}^{-1}$ (Fig. 1C). 

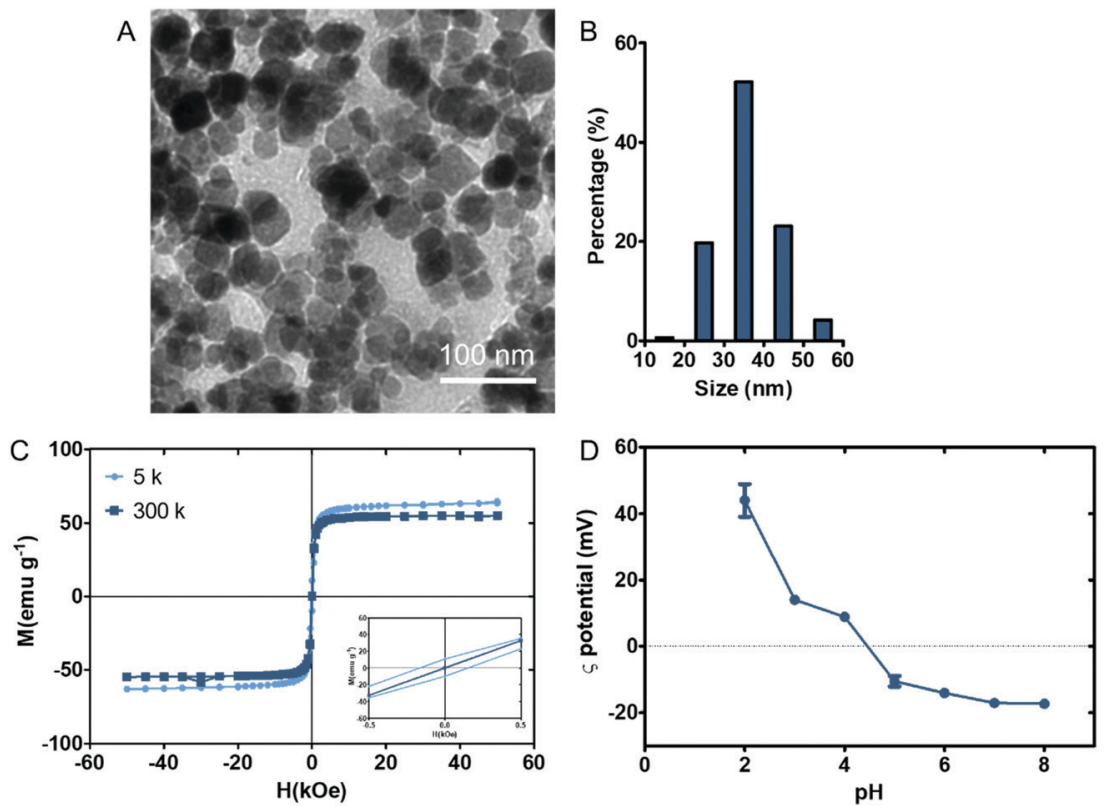

Fig. 1 Nanoparticles characterization. (A) TEM image and (B) nanoparticles size distribution. (C) Hysteresis cycle of BMNPs at $300 \mathrm{~K}$ and $5 \mathrm{~K}$. Inset: Detail of the hysteresis cycle in the absence of external magnetic field at $300 \mathrm{~K}$ and $5 \mathrm{~K}$. (D) $\zeta$-potential of BMNPs.
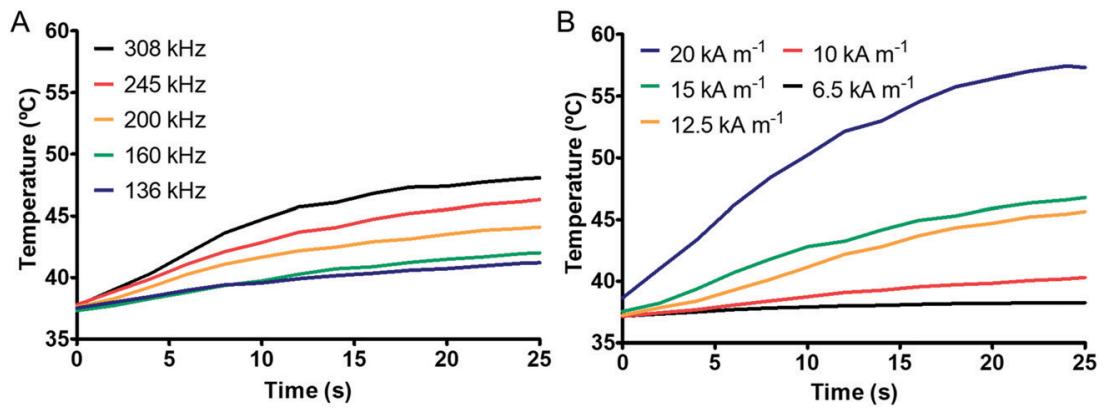

Fig. 2 Time evolution of the temperature of the BMNPs suspensions. (A) Varying frequency at a fixed magnetic field strength of $H=10 \mathrm{kA} \mathrm{m}^{-1}$, (B) varying magnetic field strengths at a fixed frequency of $136 \mathrm{kHz}$. Sample volume $0.5 \mathrm{~mL}$; particle concentration: $10 \mathrm{mg} \mathrm{mL}$.

\subsection{Alternating magnetic field response}

Alternating magnetic field responses as a function of time were obtained at four different frequencies at a fixed magnetic field strength of $10 \mathrm{kA} \mathrm{m}^{-1}$. Fig. 2A shows the time evolution of the temperature of BMNP suspensions under the presence of an AMF. For all the frequencies tested, BMNPs are able to raise the effective temperature to kill tumor cells $\left(42-46{ }^{\circ} \mathrm{C}\right)^{2,3}$ in less than $20 \mathrm{~s}$. Fig. 2B shows the temperature as a function of time for the same BMNP suspensions under the influence of different magnetic field strengths at a fixed frequency of $136 \mathrm{kHz}$. Again, a rapid increase in temperature for magnetic field strengths above $10 \mathrm{kA} \mathrm{m}^{-1}$ in a few seconds can be observed. Overall, all the samples are dependent on frequency and magnetic field strength within the evaluated range.

The SAR and ILP values are represented in Fig. 3 and Tables 1 and 2. The SAR values increase with the increase in field frequency and field strength, as mentioned. On the contrary, the intrinsic loss power is independent of frequency and field strength, displaying values within the range of
4-7 $\mathrm{nH} \mathrm{m}^{2} \mathrm{~kg}^{-1}$, which are in agreement with the results obtained by Iglesias et al. ${ }^{25}$

Note that the SAR and ILP values yielded by BMNPs are in a high range than those reported in the literature. ${ }^{26-29}$ This is interesting because previous studies have demonstrated that magnetosomes respond significantly more efficiently to AC field than magnetite nanoparticles of similar size produced chemically. ${ }^{30,31}$ The high SAR and ILP values yielded by BMNPS (chemically synthesized but in the presence of the magnetosome protein MamC) evidence that, while produced chemically (in the absence of bacteria), MamC-mediated BMNPs are not like any other chemically synthesized magnetic nanoparticle. In fact, it has already been demonstrated ${ }^{32-34}$ that MamC controls the nucleation of magnetite by template, such an effect determines the number of nuclei, and as the system is Fe limited, the effect also determines the growth of those nuclei and their final larger size. MamC also controls the kinetics of crystal growth, yielding crystals with high crystallinity that display faces which are not observed in the absence of Mamc. 

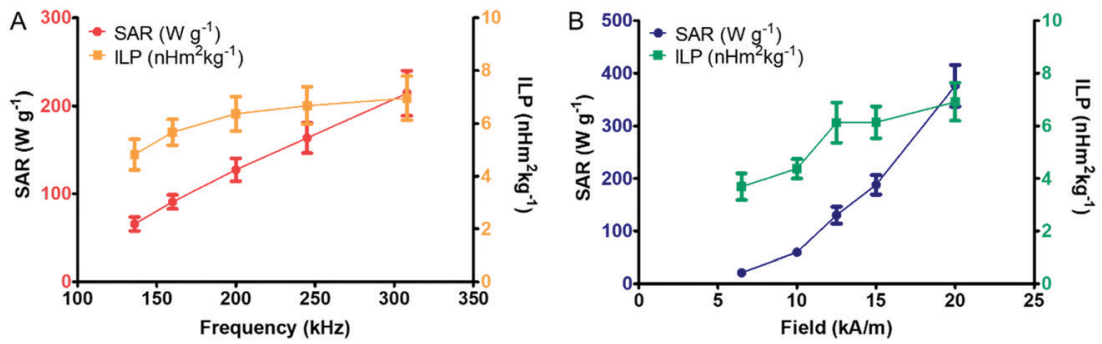

Fig. 3 SAR and ILP of the BMNPs tested. (A) Variable frequencies and fixed magnetic field strength; (B) variable magnetic field strength and fixed frequency. Sample volume $0.5 \mathrm{~mL}$; particle concentration: $10 \mathrm{mg} \mathrm{mL}^{-1}$.

Table 1 Summary of SAR and ILP calculations at different frequencies and at a fixed magnetic field intensity of $10 \mathrm{kA} \mathrm{m}^{-1}$, after $20 \mathrm{~s}$ exposition time. Sample volume $0.5 \mathrm{~mL}$; particle concentration: $10 \mathrm{mg} \mathrm{mL}^{-1}$

\begin{tabular}{llcll}
\hline System & $\begin{array}{l}\text { Frequency } \\
f[\mathrm{kHz}]\end{array}$ & $\begin{array}{l}\text { SAR } \\
{\left[\mathrm{W} \mathrm{g}^{-1}\right]}\end{array}$ & $\begin{array}{l}\text { Slope d } T / \mathrm{d} t \\
{\left[{ }^{\circ} \mathrm{C} \mathrm{s}^{-1}\right]}\end{array}$ & $\begin{array}{l}\mathrm{ILP} \\
{\left[\mathrm{nH} \mathrm{m}^{2} \mathrm{~kg}^{-1}\right]}\end{array}$ \\
\hline BMNPs & $136 \pm 5$ & $65 \pm 8$ & 0.16 & $4.8 \pm 0.6$ \\
& $160 \pm 5$ & $91 \pm 8$ & 0.22 & $5.7 \pm 0.5$ \\
& $200 \pm 5$ & $120 \pm 10$ & 0.30 & $4.7 \pm 0.6$ \\
& $245 \pm 5$ & $160 \pm 10$ & 0.39 & $6.5 \pm 0.5$ \\
& $308 \pm 5$ & $210 \pm 30$ & 0.51 & $7.0 \pm 0.8$
\end{tabular}

Table 2 Summary of SAR and ILP calculations at different magnetic field strengths and at a fixed frequency of $136 \mathrm{kHz}$, after $20 \mathrm{~s}$ exposition time. Sample volume $0.5 \mathrm{~mL}$; particle concentration: $10 \mathrm{mg} \mathrm{mL}^{-1}$

\begin{tabular}{llcll}
\hline System & $\begin{array}{l}\text { Field } \\
{\left[\mathrm{kA} \mathrm{m}^{-1}\right]}\end{array}$ & $\begin{array}{l}\text { SAR } \\
{\left[\mathrm{W} \mathrm{g}^{-1}\right]}\end{array}$ & $\begin{array}{l}\text { Slope dT/d } t \\
{\left[{ }^{\circ} \mathrm{C} \mathrm{s}^{-1}\right]}\end{array}$ & $\begin{array}{l}\text { ILP } \\
{\left[\mathrm{nH} \mathrm{m}^{2} \mathrm{~kg}^{-1}\right]}\end{array}$ \\
\hline BMNPs & $6.5 \pm 0.2$ & $21 \pm 3$ & 0.05 & $3.6 \pm 0.5$ \\
& $10 \pm 0.2$ & $60 \pm 5$ & 0.14 & $4.4 \pm 0.4$ \\
& $12.5 \pm 0.2$ & $130 \pm 20$ & 0.32 & $6.1 \pm 0.8$ \\
& $15 \pm 0.2$ & $190 \pm 20$ & 0.45 & $6.1 \pm 0.6$ \\
& $20 \pm 0.2$ & $380 \pm 25$ & 0.92 & $7.0 \pm 0.7$ \\
& & & &
\end{tabular}

All these characteristics, that are lacking in purely inorganically synthesized magnetite crystals, confer different magnetic properties as our group demonstrated previously ${ }^{18,20}$ and could account for the enhanced SAR and ILP values. The analysis of these results confirms that BMNPs will be a useful tool to generate enough heat to raise the temperature of the tumor tissue locally for the effective treatment of hyperthermia as demonstrated in previous studies. ${ }^{35,36}$

\subsection{Culture media effect}

In order to disregard the effect of culture media on magnetic hyperthermia response, as suggested previously by other authors, ${ }^{37}$ BMNPs were resuspended in MEM culture media and magnetic field experiments were again performed under identical conditions as those detailed above, but with a magnetic field strength of $H=20 \mathrm{kA} \mathrm{m}^{-1}$ and a frequency of $136 \mathrm{kHz}$. As it is shown in Fig. 4 and Table 3, the MEM cell culture medium does not affect the BMNP response to the magnetic field, and both the ILP and SAR values are similar to those obtained in the control sample (BMNPs in HEPES buffer). Therefore, these results further add that BMNPs are promising nano-heater agents, independent of the culture media used.

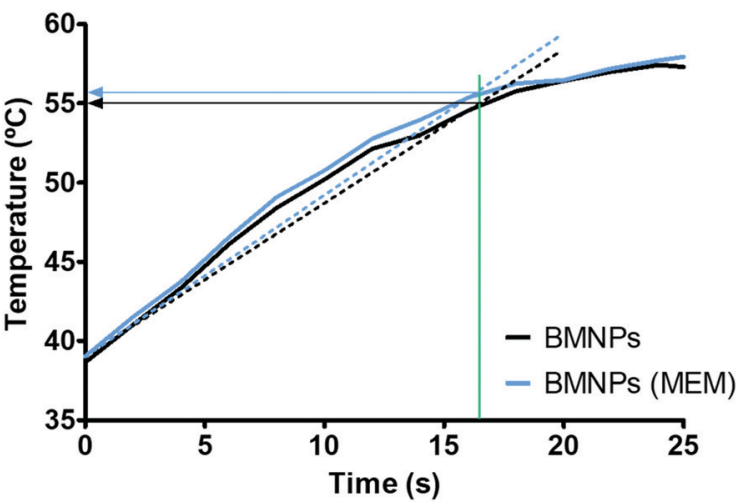

Fig. 4 Time evolution of the temperature of the BMNPs suspended in HEPES and MEM. Dash lines represent the slope of each sample curve. Magnetic field strength: $H=20 \mathrm{kA} \mathrm{m}^{-1}$. Frequency: $136 \mathrm{kHz}$. Sample volume $0.5 \mathrm{~mL}$; particle concentration: $10 \mathrm{mg} \mathrm{mL}^{-1}$.

Table 3 Summary of SAR and ILP calculations of BMNPs suspended both in HEPES buffer and MEM culture media, $H=20 \mathrm{kA} \mathrm{m}^{-1}$. Frequency $136 \mathrm{kHz}$

\begin{tabular}{llll}
\hline System & SAR $\left[\mathrm{W} \mathrm{g}^{-1}\right]$ & Slope $\mathrm{d} T / \mathrm{d} t\left[{ }^{\circ} \mathrm{C} \mathrm{s}^{-1}\right]$ & $\mathrm{ILP}\left[\mathrm{nH} \mathrm{m}^{2} \mathrm{~kg}^{-1}\right]$ \\
\hline BMNPs & $380 \pm 25$ & 0.92 & $7.0 \pm 0.3$ \\
BMNPs (MEM) & $390 \pm 25$ & 0.93 & $7.1 \pm 0.7$
\end{tabular}

\subsection{Temperature reduction by concentration or macroscopic versus microscopic temperature}

As shown before, detecting temperature rises at high concentration $\left(10 \mathrm{mg} \mathrm{mL}^{-1}\right)$ of BMNPs is not difficult. However, when the concentration of BMNPs is reduced to a point that is not cytotoxic $\left[300 \mu \mathrm{g} \mathrm{mL}^{-1}\right.$ for our $\mathrm{BMNPs}^{6}$ or $100 \mu \mathrm{g} \mathrm{mL}{ }^{-1}$ for many publications ${ }^{38,39}$, problems arise because at such low concentrations, temperature increases can be negligible and in some cases, extremely difficult to measure. At higher magnetic nanoparticle concentrations, SAR values can be measured as shown before, and a correlation between SAR, nanoparticle concentration, magnetic field strength, and frequency can be determined (Fig. 3). At a given frequency, magnetic field strength, and particle concentration, SAR value can be calculated from the initial slope of the Temperature versus time (d $T / \mathrm{d} t$, Fig. 4) curve by using eqn (1). As an example, considering a field of $20 \mathrm{kA} \mathrm{m}^{-1}$, a frequency of $136 \mathrm{kHz}$, and a concentration of $10 \mathrm{mg} \mathrm{mL}^{-1}$, the SAR value for our BMNPs is $380 \mathrm{~W} \mathrm{~g}^{-1}$ with 
a slope of $0.92{ }^{\circ} \mathrm{C} \mathrm{s}^{-1}$ for the first $30 \mathrm{~s}$ (Tables 2 and 3). Using this value as a reference, under identical conditions, for the concentration of BMNPs equal to $300 \mu \mathrm{g} \mathrm{mL}{ }^{-1}$ (nearly thirty-times lower than $10 \mathrm{mg} \mathrm{mL}^{-1}$, which is the concentration used in the in vitro cytotoxicity test), it can be predicted that the temperature increase will be lower than $0.03{ }^{\circ} \mathrm{C} \mathrm{s}^{-1}$, which is certainly very difficult to measure. Even more, if we consider that the sample, the coil, and the environment have to be heat-controlled and kept at $37{ }^{\circ} \mathrm{C}$ operating under adiabatic conditions and that any disturbance around could affect the measurement.

Given such a difficulty, and considering that the concentration of magnetic nanoparticles is limited by the dose at which they become cytotoxic, the only possibility to obtain measurable temperature increases (as published by many authors) is to raise both the frequency and intensity of the magnetic field applied. However, there is also a tolerable clinical limit for these magnitudes, which cannot be exceeded. This is based on the product of field strength and frequency, and it should not exceed $4.85 \times 10^{8} \mathrm{~A} \mathrm{~m}^{-1} \mathrm{~s}^{-1},{ }^{40}$ or $H-f \leq 5 \times$ $10^{9} \mathrm{~A} \mathrm{~m}^{-1} \mathrm{~s}^{-1}$ as proposed by Dutz and Hergt, ${ }^{5}$ a limit overcome in many in vitro tests published. The frequency and magnetic field strength used in this study $\left(H=20 \mathrm{kA} \mathrm{m}^{-1}\right.$, frequency: $136 \mathrm{kHz}, H-f \sim 2.7 \times 10^{9} \mathrm{~A} \mathrm{~m}^{-1} \mathrm{~s}^{-1}$ ) were chosen by taking into account this $H-f$ limitation and so was the BMNP concentration range.

Under these conditions, the temperature increase as a function of BMNP concentration (from $100 \mu \mathrm{g} \mathrm{mL}^{-1}$ to $20 \mathrm{mg} \mathrm{mL}^{-1}$ ) was tried to be measured by using a thermographic camera. As can be seen in the thermal photograph in Fig. 5A, only high

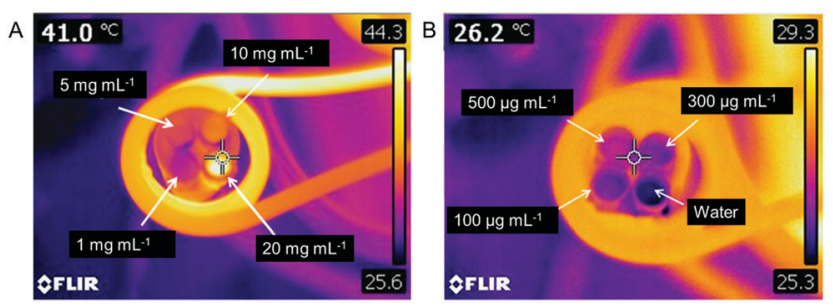

Fig. 5 Thermographic photographs of different particle concentrations. (A) High concentration of BMNPs and (B) low concentration of BMNPs. Magnetic field strength of $20 \mathrm{kA} \mathrm{m}^{-1}$ and frequency of $136 \mathrm{kHz}$, for 5 minutes test. concentrations of BMNPs (>5 $\mathrm{mg} \mathrm{mL}^{-1}$ ) show a significant increase in temperature. Conversely, when BMNP concentrations are lower than $1 \mathrm{mg} \mathrm{mL} \mathrm{m}^{-1}$, as in our in vitro experiment, the temperature increase was not significant, and thus it was not expected to be high enough to cause cell death. However, interestingly, cell death did occur as shown below.

\subsection{BMNP cell internalization}

When incubated with $300 \mu \mathrm{g} \mathrm{mL} \mathrm{m}^{-1}$ BMNPs, these BMNPs are internalized via endocytosis as demonstrated by Jabalera et al. ${ }^{24}$ Cell internalization in present experiments was indirectly determined by measuring the intracellular iron and also, by observing this internalization by TEM. As can be seen in Fig. 6A, the TEM micrographs show that there is BMNP internalization in HepG2 cells, and $\sim 108 \mu \mathrm{g} \mathrm{mL}^{-1}$ of BMNPs (36\%) are internalized as shown in Fig. 6B.

\subsection{Cytotoxicity and ROS evaluation}

Cytotoxicity tests run by adding $300 \mu \mathrm{g} \mathrm{mL} \mathrm{m}^{-1}$ of BMNPs to HepG2 cells in the presence or absence of an alternating magnetic field show that, at this concentration, BMNPs were cytocompatible in the absence of AFM, but they become significantly cytotoxic in the presence of AFM (Fig. 7A). In fact, under the influence of AMF, BMNPs reduced HepG2 cell viability by $30 \%$ after $2 \mathrm{~h}$. These results are in agreement with those obtained in the literature; ${ }^{24}$ although, the reason for cytotoxicity could not be elucidated by these authors at that moment. The fact that BMNPs become cytotoxic in the presence of AMF was very interesting, especially because as stated above, the temperature would rise enough to reach the $42{ }^{\circ} \mathrm{C}$ threshold (Fig. 5). Therefore, temperature rise could not be claimed to explain the cytotoxicity of BMNPs in the presence of AMF.

Interestingly, Fig. 7B shows that only in cells incubated with BMNPs under AMF conditions, there was a significant intracellular ROS production $(\times 100)$. This is relevant because ROS is a well-known factor to cause cellular damage and it is precise when cell viability was reduced and ROS production was detected. Therefore, since temperature rise cannot be claimed for this kind of cytotoxicity, we hypothesize that the increase of intracellular ROS levels caused by the AMF applied to cells containing BMNPs is responsible for cell death. It has been widely described that the main sources of cellular ROS are
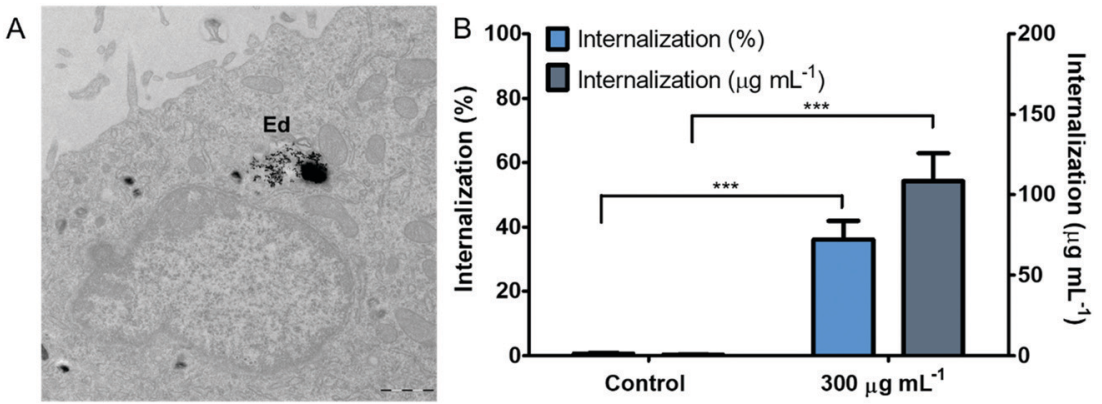

Fig. 6 (A) TEM image of BMNPs compartmentalized in endosomes (Ed). (B) Quantitative analyses of BMNPs cellular uptake in HepG2. These experiments were conducted twice in triplicates. ${ }^{* \star} p<0.001$. 

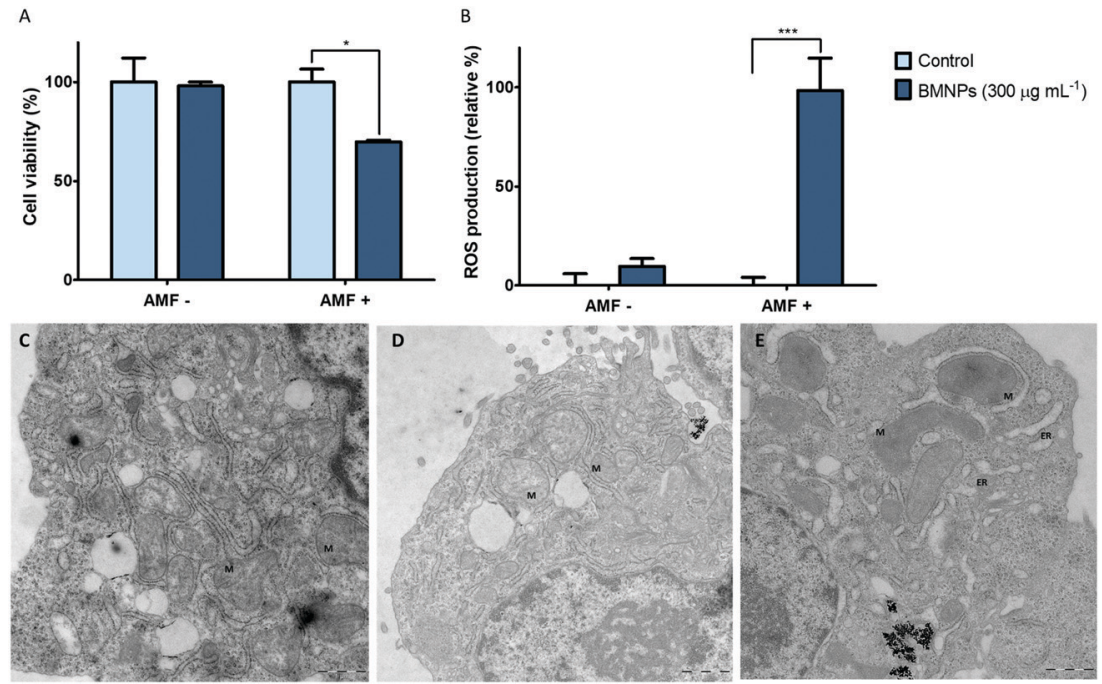

Fig. 7 Effect of exposure of alternating magnetic field (AMF) on (A) cell viability and (B) intracellular ROS levels in HepG2. These experiments were conducted twice in triplicates. ${ }^{*} p<0.05,{ }^{* *} p<0.001$. Ultrastructural alteration produced by AMF: (C) control HepG2 cells, (D) cells incubated with BMNPs showed normal mitochondria (M) morphology. (E) Abnormally shaped and swollen mitochondria with disorganised cristae (M) and endoplasmic reticulum (ER) such dilatation occurring in cells incubated with BMNPs under AMF condition.

mitochondria and endoplasmic reticulum (ER). Our results obtained from cells incubated with BMNPs having concentration $300 \mu \mathrm{g} \mathrm{mL} \mathrm{m}^{-1}$ under AMF show mitochondrial swelling with disorganized cristae and vacuolization in ER cisternae (Fig. 7E). Several authors reported that mitochondrial dysfunction generates ROS, which profoundly alters cellular physiology, and as a consequence, ROS production by ER is activated. ${ }^{41,42}$ In this context, a rise in cytosolic ROS production can be observed indirectly from mitochondrial dysfunction as described by Leadsham et al. ${ }^{43}$ Our results are in agreement with those obtained by these authors and confirm that the aberrant mitochondrial morphology could be responsible for the rise in ROS production observed in these cells. None of these ultrastructural aberrations were observed in cells in the absence of AMF (Fig. 7C and D).

AMF has been previously observed to cause cell death in cells incubated with magnetic nanoparticles as stated above, and temperature rises were claimed to be responsible for such death. ${ }^{7-9}$ However, either an over-recommended pair $(f, H)$ was applied $^{44}$ or too large concentrations of magnetic nanoparticles were used ${ }^{6}$ in many studies published so far. Other studies have described non-temperature mediated processes to explain the cell death of cells incubated with magnetic nanoparticles upon exposure to AMF. In particular, Kozissnik et al. ${ }^{45}$ proposed a magnetically mediated energy delivery causing selective cell death or damage to intracellular structures due to the rotation/translation of magnetic nanoparticles upon the application of AMF.

Here we propose another alternative mechanism to explain non-temperature mediated cell death following upon exposure of cells containing BMNPs to AMF: intracellular ROS production. It is worth noting that, under our experimental conditions, such an intracellular ROS increase is not linked to a significant temperature rise caused by AMF. Our results demonstrate that the observed increase in intracellular ROS caused by AMF is related to mitochondrial dysfunction. Nevertheless, other parameters may also account for that, such as the movement/rotation of BMNPs upon AMF application, which may cause the cell damage in intracellular structures. In fact, the rotation of BMNPs after AMF application has previously been shown to break liposomes containing BMNPs. ${ }^{35}$ This hypothesis is in line with the findings of Kozissnik et al. ${ }^{45}$ Another parameter that may also account for intracellular ROS production is the release of Fe from endocitic nanoparticles. If BMNPs enters the cell through endocytosis, as proposed in the literature ${ }^{46}$ the acidic medium of lysosomes would partially dissolve BMNPs and increase the bioavailability of intracellular Fe, which, in turn, by means of the Fenton reaction, would also result in ROS increase. ${ }^{47-49}$ Finally, the induction of heat localized at nanoscale around magnetic nanoparticles without detectable macroscopic temperature rise should also be considered as a potential cause of intracellular ROS production. Such a nanoscale localized temperature rise could contribute to alterations in cell physiology, resulting in ROS production and/ or cell death. ${ }^{1,50}$

\section{Conclusions}

The limitations conditioned by the $(f, H)$ pair added to the low doses of magnetite nanoparticles required to prevent in vitro and in vivo temperature rises to reach the minimum threshold necessary for causing cell death (temperature mediated) after the application of AMF on cells incubated with magnetic nanoparticles. However, cell death occurs even if this threshold is not reached, and the mechanisms underlying this kind of cell death are still unknown. The results from the present study show that intracellular ROS production following upon AMF 
exposure of HepG2 cells containing BMNPs could be claimed to explain the loss of cell viability without significant temperature rises. This type of ROS production is linked to mitochondrial dysfunction caused by the application of AMF to cells containing BMNPs, and is not observed under these conditions in the absence of AMF. This study attempts to identify and understand the molecular mechanisms by which AMF causes cell death, without mediating temperature, in cells containing magnetic nanoparticles. These results could be exploited to increase the efficiency of cancer treatments mediated by the application of AMF to cells containing BMNPs, since cell death could be potentiated by promoting the production of intracellular ROS. Further research needs to be done in order to define and control the mechanisms that contribute to ROS production under these conditions with a goal of continuously developing new ways to increase the efficiency of magnetic hyperthermia as an alternative cancer treatment.

\section{Conflicts of interest}

The authors declare no conflict of interest.

\section{Acknowledgements}

This research work is supported by Ministerio de Economía y Competitividad (CGL2016-76723 project), Ramón y Cajal programme (RYC-2014-16901), Junta de Andalucía. Programa Operativo FEDER 2014-2020. (A1-FQM-341-UGR18, C-FQM-497UGR18, A-BIO-376-UGR18). This research was also aided by the Andalusian regional government (CTS-236). Alberto Sola-Leyva holds a Formación de Doctores 2018 grant (ref. PRE2018085440) from the Ministerio de Ciencia, Innovación y Universidades (Spain). Ylenia Jabalera wants to acknowledge a FPU2016 grant (ref. FPU16_04580) from the Ministerio de Educación, Ciencia y Deporte y Competitividad (Spain) and Unidad Cientifica de Excelencia UCE-PP2016-05 of the University of Granada. This study is part of a PhD Thesis conducted at the University of Granada, Spain. Finally, thanks go to the CIC personnel of the University of Granada for technical assistance in the TEM.

\section{References}

1 X. Liu, Y. Zhang, Y. Wang, W. Zhu, G. Li and X. Ma, et al., Comprehensive understanding of magnetic hyperthermia for improving antitumor therapeutic efficacy, Theranostics, 2020, 10(8), 3793-3815.

2 L. H. Reddy, J. L. Arias, J. Nicolas and P. Couvreur, Magnetic nanoparticles: Design and characterization, toxicity and biocompatibility, pharmaceutical and biomedical applications, Chem. Rev., 2012, 112, 5818-5878.

3 D. L. Huber, Synthesis, properties, and applications of iron nanoparticles, Small, 2005, 1, 482-501.

4 C. S. S. R. Kumar and F. Mohammad, Magnetic nanomaterials for hyperthermia-based therapy and controlled drug delivery, Adv. Drug Delivery Rev., 2011, 63, 789-808.
5 S. Dutz and R. Hergt, Magnetic nanoparticle heating and heat transfer on a microscale: Basic principles, realities and physical limitations of hyperthermia for tumour therapy, Int. J. Hyperthermia, 2013, 29(8), 790-800, DOI: 10.3109/ 02656736.2013.822993.

6 Y. Jabalera, B. Garcia-Pinel, R. Ortiz, G. Iglesias, L. Cabeza and J. Prados, et al., Oxaliplatin-Biomimetic Magnetic Nanoparticle Assemblies for Colon Cancer-Targeted Chemotherapy: An In Vitro Study, Pharmaceutics, 2019, 11(8), 395.

7 S. Matsuda, E. Nakajima, T. Nakanishi, A. Hitsuji, H. Zhang and A. Tanaka, et al., Effective induction of death in mesothelioma cells with magnetite nanoparticles under an alternating magnetic field, Mater. Sci. Eng., C, 2017, 81, 90-96, DOI: 10.1016/j.msec.2017.07.023.

8 S. E. Minaei, S. Khoei, S. Khoee, F. Vafashoar and V. P. Mahabadi, In vitro anti-cancer efficacy of multi-functionalized magnetite nanoparticles combining alternating magnetic hyperthermia in glioblastoma cancer cells, Mater. Sci. Eng., C, 2019, 101(April), 575-587, DOI: 10.1016/j.msec.2019.04.007.

9 V. Vilas-Boas, B. Espina, Y. V. Kolen'Ko, M. Banobre-López, M. Brito and V. Martins, et al., Effectiveness and Safety of a Nontargeted Boost for a CXCR4-Targeted Magnetic Hyperthermia Treatment of Cancer Cells, ACS Omega, 2019, 4(1), 1931-1940.

10 S. M. Carvalho, A. G. Leonel, A. A. P. Mansur, I. C. Carvalho, K. Krambrock and H. S. Mansur, Bifunctional magnetopolymersomes of iron oxide nanoparticles and carboxymethylcellulose conjugated with doxorubicin for hyperthermo-chemotherapy of brain cancer cells, Biomater. Sci., 2019, 7(5), 2102-2122, DOI: 10.1039/c8bm01528g.

11 A. G. Leonel, H. S. Mansur, A. A. P. Mansur, A. Caires, S. M. Carvalho and K. Krambrock, et al., Synthesis and characterization of iron oxide nanoparticles/carboxymethyl cellulose core-shell nanohybrids for killing cancer cells in vitro, Int. J. Biol. Macromol., 2019, 132, 677-691, DOI: 10.1016/j.ijbiomac.2019.04.006.

12 K. Parekh, A. Bhardwaj and N. Jain, Preliminary in-vitro investigation of magnetic fluid hyperthermia in cervical cancer cells, J. Magn. Magn. Mater., 2020, 497(October 2019), 166057, DOI: 10.1016/j.jmmm.2019.166057.

13 M. Saeedi, O. Vahidi and S. Bonakdar, Synthesis and characterization of glycyrrhizic acid coated iron oxide nanoparticles for hyperthermia applications, Mater. Sci. Eng., C, 2017, 77, 1060-1067, DOI: 10.1016/j.msec.2017.04.015.

14 M. Salimi, S. Sarkar, R. Saber, H. Delavari, A. M. Alizadeh and H. T. Mulder, Magnetic hyperthermia of breast cancer cells and MRI relaxometry with dendrimer-coated ironoxide nanoparticles, Cancer Nanotechnol., 2018, 9(1), 7, DOI: $10.1186 / \mathrm{s} 12645-018-0042-8$.

15 T. Mai and J. Z. Hilt, Magnetic nanoparticles: reactive oxygen species generation and potential therapeutic applications, J. Nanopart. Res., 2017, 19(7), 253, DOI: 10.1007/ s11051-017-3943-2.

16 R. J. Wydra, P. G. Rychahou, B. M. Evers, K. W. Anderson, T. D. Dziubla and J. Z. Hilt, The role of ROS generation from magnetic nanoparticles in an alternating magnetic field on 
cytotoxicity, Acta Biomater., 2015, 25, 284-290, DOI: 10.1016/ j.actbio.2015.06.037.

17 C. Fleury, B. Mignotte and J.-L. Vayssière, Mitochondrial reactive oxygen species in cell death signaling, Biochimie, 2002, 84(2-3), 131-141.

18 C. Valverde-Tercedor, M. Montalbán-López, T. Perez-Gonzalez, M. S. Sanchez-Quesada, T. Prozorov and E. Pineda-Molina, et al., Size control of in vitro synthesized magnetite crystals by the MamC protein of Magnetococcus marinus strain MC-1, Appl. Microbiol. Biotechnol., 2015, 99(12), 5109-5121.

19 T. Perez-Gonzalez, C. Jimenez-Lopez, A. L. Neal, F. RullPerez, A. Rodriguez-Navarro and A. Fernandez-Vivas, et al., Magnetite biomineralization induced by Shewanella oneidensis, Geochim. Cosmochim. Acta, 2010, 74(3), 967-979.

20 G. García Rubia, A. Peigneux, Y. Jabalera, J. Puerma, F. Oltolina and K. Elert, et al., pH-Dependent Adsorption Release of Doxorubicin on MamC-Biomimetic Magnetite Nanoparticles, Langmuir, 2018, 34(45), 13713-13724, DOI: 10.1021/acs.langmuir.8b03109.

21 I. Obaidat, B. Issa and Y. Haik, Magnetic Properties of Magnetic Nanoparticles for Efficient Hyperthermia, Nanomaterials, 2015, 5(1), 63-89.

22 R. R. Wildeboer, P. Southern and Q. A. Pankhurst, On the reliable measurement of specific absorption rates and intrinsic loss parameters in magnetic hyperthermia materials, J. Phys. D: Appl. Phys., 2014, 47, 495003.

23 A. Sola-Leyva, L. C. López-Cara, P. Ríos-Marco, A. Ríos, C. Marco and M. P. Carrasco-Jiménez, Choline kinase inhibitors EB-3D and EB-3P interferes with lipid homeostasis in HepG2 cells, Sci. Rep., 2019, 9(1), 5109, DOI: 10.1038/s41598-019-40885-z.

24 Y. Jabalera, A. Sola-Leyva, A. Peigneux, F. Vurro, G. R. Iglesias and J. Vilchez-Garcia, et al., Biomimetic Magnetic Nanocarriers Drive Choline Kinase Alpha Inhibitor inside Cancer Cells for Combined Chemo-Hyperthermia Therapy, Pharmaceutics, 2019, 11(8), 408.

25 G. R. Iglesias, F. Reyes-Ortega, B. L. C. Fernandez and Á. V. Delgado, Hyperthermia-triggered gemcitabine release from polymer-coated magnetite nanoparticles, Polymers, 2018, 10(3), 269.

26 B. Clares, R. A. Biedma-Ortiz, E. Sáez-Fernández, J. C. Prados, C. Melguizo and L. Cabeza, et al., Nano-engineering of 5-fluorouracil-loaded magnetoliposomes for combined hyperthermia and chemotherapy against colon cancer, Eur. J. Pharm. Biopharm., 2013, 85(3), 329-338.

27 M. Muñoz de Escalona, E. Sáez-Fernández, J. C. Prados, C. Melguizo and J. L. Arias, Magnetic solid lipid nanoparticles in hyperthermia against colon cancer, Int. J. Pharm., 2016, 504(1-2), 11-19.

28 E. Cheraghipour, S. Javadpour and A. R. Mehdizadeh, Citrate capped superparamagnetic iron oxide nanoparticles used for hyperthermia therapy, J. Biomed. Sci. Eng., 2012, 5(12), 715-719.

29 Z. Li, M. Kawashita, N. Araki, M. Mitsumori and M. Hiraoka, Magnetite nanoparticles with high heating efficiencies for application in the hyperthermia of cancer, Mater. Sci. Eng., C, 2010, 30(7), 990-996.
30 A. E. Deatsch and B. A. Evans, Heating efficiency in magnetic nanoparticle hyperthermia, J. Magn. Magn. Mater., 2014, 354, 163-172.

31 R. Hergt, R. Hiergeist, M. Zeisberger, D. Schüler, U. Heyen and I. Hilger, et al., Magnetic properties of bacterial magnetosomes as potential diagnostic and therapeutic tools, J. Magn. Magn. Mater., 2005, 80-86.

32 R. Lopez-Moreno, A. Fernández-Vivas, C. Valverde-Tercedor, A. I. Azuaga Fortes, S. Casares Atienza and A. B. RodriguezNavarro, et al., Magnetite Nanoparticles Biomineralization in the Presence of the Magnetosome Membrane Protein MamC: Effect of Protein Aggregation and Protein Structure on Magnetite Formation, Cryst. Growth Des., 2017, 17(4), 1620-1629, DOI: 10.1021/acs.cgd.6b01643.

33 A. Ubago-Rodríguez, S. Casares Atienza, A. Fernández-Vivas, A. Peigneux, Y. Jabalera and M. de la Cuesta-Rivero, et al., Structure-Function of MamC Loop and Its Effect on the in Vitro Precipitation of Biomimetic Magnetite Nanoparticles, Cryst. Growth Des., 2019, 19(5), 2927-2935, DOI: 10.1021/ acs.cgd.9b00150.

34 Y. Jabalera, S. Casares Atienza, A. Fernández-Vivas, A. Peigneux, A. I. Azuaga Fortes and C. Jimenez-Lopez, Protein Conservation Method Affects MamC-Mediated Biomineralization of Magnetic Nanoparticles, Cryst. Growth Des., 2019, 19(2), 1064-1071, DOI: 10.1021/acs.cgd.8b01590.

35 Y. Jabalera, A. Fernández-Vivas, G. R. Iglesias, Á. V. Delgado and C. Jimenez-Lopez, Magnetoliposomes of mixed biomimetic and inorganic magnetic nanoparticles as enhanced hyperthermia agents, Colloids Surf., B, 2019, 183(August), 110435, DOI: 10.1016/j.colsurfb.2019.110435.

36 G. R. Iglesias, Y. Jabalera, A. Peigneux, B. L. Checa Fernández, Á. V. Delgado and C. Jimenez-Lopez, et al., Enhancement of Magnetic Hyperthermia by Mixing Synthetic Inorganic and Biomimetic Magnetic Nanoparticles, Pharmaceutics, 2019, 11(6), 273.

37 M. Suto, Y. Hirota, H. Mamiya, A. Fujita, R. Kasuya and K. Tohji, et al., Heat dissipation mechanism of magnetite nanoparticles in magnetic fluid hyperthermia, J. Magn. Magn. Mater., 2009, 321(10), 1493-1496.

38 M. Khalid, M. Asad, P. Henrich-Noack, M. Sokolov, W. Hintz and L. Grigartzik, et al., Evaluation of Toxicity and Neural Uptake In Vitro and In Vivo of Superparamagnetic Iron Oxide Nanoparticles, Int. J. Mol. Sci., 2018, 19(9), 2613.

39 R. M. Patil, N. D. Thorat, P. B. Shete, P. A. Bedge, S. Gavde and M. G. Joshi, et al., Comprehensive cytotoxicity studies of superparamagnetic iron oxide nanoparticles, Biochem. Biophys. Rep., 2018, 13, 63-72.

40 W. J. Atkinson, I. A. Brezovich and D. P. Chakraborty, Usable Frequencies in Hyperthermia with Thermal Seeds, IEEE Trans. Biomed. Eng., 1984, BME-31(1), 70-75.

41 J. Ježek, K. Cooper and R. Strich, Reactive Oxygen Species and Mitochondrial Dynamics: The Yin and Yang of Mitochondrial Dysfunction and Cancer Progression, Antioxidants, 2018, 7(1), 13.

42 M. P. Murphy, Mitochondrial Dysfunction Indirectly Elevates ROS Production by the Endoplasmic Reticulum, Cell Metab., 2013, 18(2), 145-146. 
43 J. E. Leadsham, G. Sanders, S. Giannaki, E. L. Bastow, R. Hutton and W. R. Naeimi, et al., Loss of Cytochrome $c$ Oxidase Promotes RAS-Dependent ROS Production from the ER Resident NADPH Oxidase, Yno1p, in Yeast, Cell Metab., 2013, 18(2), 279-286.

44 A. Jordan, R. Scholz, P. Wust, H. Fak and R. Felix, Magnetic fluid hyperthermia (MFH): Cancer treatment with AC magnetic field induced excitation of biocompatible superparamagnetic nanoparticles, J. Magn. Magn. Mater., 1999, 201, 413-419.

45 B. Kozissnik, A. C. Bohorquez, J. Dobson and C. Rinaldi, Magnetic fluid hyperthermia: Advances, challenges, and opportunity, Int. J. Hyperthermia, 2013, 29(8), 706-714, DOI: $10.3109 / 02656736.2013 .837200$.

46 C. Wilhelm, F. Gazeau, J. Roger, J. N. Pons and J.-C. Bacri, Interaction of Anionic Superparamagnetic Nanoparticles with Cells: Kinetic Analyses of Membrane Adsorption and Subsequent Internalization, Langmuir, 2002, 18(21), 8148-8155, DOI: $10.1021 / \mathrm{la0257337.}$
47 J. Rejman, V. Oberle, I. S. Zuhorn and D. Hoekstra, Sizedependent internalization of particles via the pathways of clathrin- and caveolae-mediated endocytosis, Biochem. J., 2004, 377(1), 159-169.

48 P. Clerc, P. Jeanjean, N. Hallali, M. Gougeon, B. Pipy and J. Carrey, et al., Targeted Magnetic Intra-Lysosomal Hyperthermia produces lysosomal reactive oxygen species and causes Caspase-1 dependent cell death, J. Controlled Release, 2018, 270, 120-134.

49 M. Domenech, I. Marrero-Berrios, M. Torres-Lugo and C. Rinaldi, Lysosomal Membrane Permeabilization by Targeted Magnetic Nanoparticles in Alternating Magnetic Fields, ACS Nano, 2013, 7(6), 5091-6101, DOI: 10.1021/ nn4007048.

50 E. Cazares-Cortes, S. Cabana, C. Boitard, E. Nehlig, N. Griffete and J. Fresnais, et al., Recent insights in magnetic hyperthermia: From the "hot-spot" effect for local delivery to combined magneto-photo-thermia using magneto-plasmonic hybrids, Adv. Drug Delivery Rev., 2019, 138, 233-246. 